\title{
Varied light and scanning electron microscopic appearances of barium sulphate in smears and histological sections
}

\author{
DA LEVISON, PR CROCKER, A SMITH, AJ BLACKSHAW, CI BARTRAM* \\ From the Departments of Histopathology and *Radiology, St Bartholomew's Hospital and Medical College, \\ London ECIA $7 B E$
}

SUMMARY The various light and scanning electron microscopic appearances of barium sulphate in smears and in histopathological lesions in sections are illustrated. One type of barium sulphate (E-Z-HD) includes much larger, bright birefringent particles and has very different appearances from other widely used types. Such larger particles in sections were not originally suspected to be barium sulphate and were identified only by energy dispersive $x$ ray analysis in a scanning electron microscope. This form of barium sulphate is used for double contrast upper gastrointestinal radiography, and is not thought to have been responsible for the lesions in which it has been observed by us.

Barium sulphate, used in colloidal suspension as a contrast medium mainly in the gastrointestinal tract, seems to be remarkably non-irritant. Not infrequently, it is seen in macrophages and giant cells in the lamina propria or submucosa of the bowel wall after barium meal or enema examinations, but only rarely does its presence in the tissues seem to produce symptoms..$^{1-4}$ We were recently puzzled by the presence of large bright doubly refractile particles (Fig. 1) in the submucosa of a segment of small bowel resected because of ischaemic enteritis. It was not until we examined these particles in paraffin sections by $x$ ray energy spectroscopy in a scanning electron microscope that we discovered that they were particles of barium sulphate. This prompted us to examine other patients' sections suspected to contain barium sulphate and also the five different barium sulphate preparations used in St Bartholomew's and St Mark's hospitals. Examination was by light microscopy, scannning electron microscopy (secondary electron image and backscattered electron image), and $x$ ray energy spectroscopy.

\section{Material and methods}

BARIUM SULPHATE SAMPLES

Samples of the five forms of barium sulphate used as a gastrointestinal contrast medium in St Bartholomew's and St Mark's hospitals were examined

Accepted for publication 16 January 1984 after spreading the material on a glass slide. Glass slides were used throughout in order to standardise results between these test samples and glass mounted histological sections. The types of barium examined in this way were Micropaque (Nicholas Aspro), Baritop 100 (Concept Pharmaceuticals Ltd), Unibaryt (Rotim Pharma, GmbH Weiterstadt, West Germany), Polibar ACB, and E-Z-HD (E-Z-EM Co Inc, Westbury, New York-British licence holder Henley's Medical Supplies Ltd, London). Micropaque, Baritop 100, and Unibaryt were supplied in suspension as white odourless liquids. Polibar ACB, designed for use in the colon, was supplied as a white odourless powder, and E-Z-HD, designed for upper gastrointestinal double contrast radiographic investigations, was supplied as a pink sweet smelling powder. In contains added sweetener and flavouring to make it more palatable.

To obtain standard conditions for examination the three bariums in suspension were dried; each sample was packed into a $2 \mathrm{ml}$ vial and weighed. Two milligrams of each sample was then suspended in $2 \mathrm{ml}$ of distilled water and mixed, and one drop from each was allowed to dry out on a glass slide. This produced a layer which was dense in the centre and thinner towards the edges, thus reproducing the variable thickness of the groups of barium sulphate particles seen in histological sections. These layers were carbon coated and examined in a Jeol 35CF scanning electron microscope in the secondary electron and backscattered electron modes, and by energy 
dispersive $x$ ray spectroscopy (XES) using a Kevex 7000 system. XES was performed using a $25 \mathrm{kV}$ accelerating voltage and 20 random areas of each sample were analysed, each being counted for 100 seconds.

\section{PATIENT MATERIAL}

The clinical details of the five patients from whom histopathological sections were selected for exami- nation are summarised in Table 1 . Case 1 is the case referred to in the introduction which stimulated this study, where large birefringent crystals of barium sulphate were found in jejunal submucosa. Case 2 showed similar large crystals in the bases of two chronic gastric ulcers, while cases 3,4 , and 5 all showed histological lesions with macrophages containing finely granular weakly birefringent material, which, because of its classic appearance, was 
Table 1 Details of the five cases from whom histopathological lesions were examined

\begin{tabular}{|c|c|c|c|c|}
\hline Case & Pathological diagnosis & Pathological specimen & $\begin{array}{l}\text { Size of barium sulphate } \\
\text { particles and refractility }\end{array}$ & $\begin{array}{l}\text { Site of barium sulphate } \\
\text { particles }\end{array}$ \\
\hline 1 & Ischaemic enteritis & Segment of jejunum & 4-50 $\mu \mathrm{m}$ strong & \multirow{5}{*}{$\begin{array}{l}\text { Submucosa, free and in } \\
\text { lymphatics } \\
\text { Submucosa, free and in } \\
\text { lymphatics } \\
\text { In macrophages in } \\
\text { peridiverticular abscess } \\
\text { In macrophages in mucosal } \\
\text { plaque } \\
\text { In macrophages in mucosa }\end{array}$} \\
\hline 2 & Chronic peptic ulcer & Partial gastrectomy & 4-50 $\mu \mathrm{m}$ strong & \\
\hline 3 & $\begin{array}{l}\text { Diverticular disease } \\
\text { (peridiverticular abscess) }\end{array}$ & Segment of sigmoid polon & $<1 \mu \mathrm{m}$ weak & \\
\hline 4 & Diverticular disease & Segment of sigmoid colon & $<1 \mu \mathrm{m}$ weak & \\
\hline 5 & Ulcerative colitis & Rectal biopsy & $<1 \mu \mathrm{m}$ weak & \\
\hline
\end{tabular}

strongly suspected to be barium sulphate. ${ }^{23}$ The clinical notes of these five patients confirmed that all had had previous gastrointestinal examinations in which barium sulphate was used.

From these surgical specimens formalin fixed, paraffin embedded, haematoxylin and eosin stained sections suspected to contain barium sulphate were examined and photographed by light microscopy with and without cross polarised light. The coverslips were then removed, and the sections were coated with carbon and placed in a Jeol 35CF scanning electron microscope. The area suspected to contain barium sulphate was identified and then examined in exactly the same way as the test samples and as desribed elsewhere. ${ }^{10}$

\section{Results}

\section{BARIUM SULPHATE SAMPLES}

The approximate weights of $2 \mathrm{ml}$ dried volumes of the test samples were as follows: Micropaque $3 \cdot 20 \mathrm{~g}$,
Baritop $2.95 \mathrm{~g}$. Unibaryt $2.90 \mathrm{~g}$, Polibar ACB $2.75 \mathrm{~g}$, and E-Z-EM HD $3.79 \mathrm{~g}$. Light microscopic examination of smears of Micropaque, Baritop 100, Unibaryt, and Polibar ACB showed that all four consisted of very similar small sized particles less than $1 \mu \mathrm{m}$ in diameter. Fig. 2a shows the light microscopic appearances of Micropaque. Under cross polarised light these four types of barium sulphate were only very weakly birefringent. On the other hand, E-Z-HD, similarly examined by light microscopy, was made up of a mixture of particles of varying sizes: there was a population of small particles $<1.0 \mu \mathrm{m}$ in diameter and a population of larger particles ranging from 4 to $50 \mu \mathrm{m}$ in diameter (Fig. 2b). The small particles of E-Z-HD were weakly birefringent, but the larger particles were brightly doubly refractile when viewed under cross polarised light (Fig. 2c).

Scanning electron microscopic examination of the smears of Micropaque, Baritop 100, Unibaryt, and Polibar ACB in the secondary electron mode (stan-

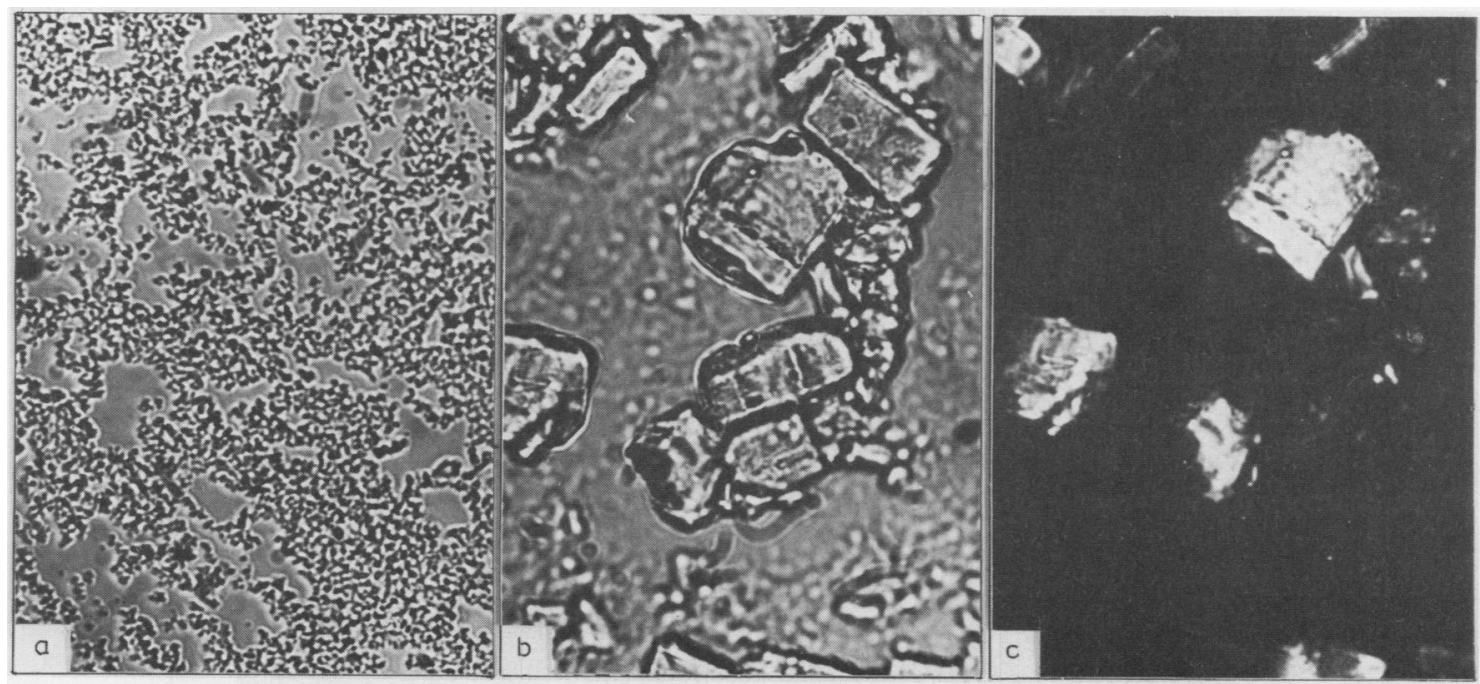

Fig. 2 Light micrographs of smears of barium sulphate all $\times 1200$. (a) is Micropaque; (b) and (c) are the same area of E-Z-HD, (c) under cross polarised light. The particles in (a) are uniformly small. In addition to the background small particles in (b), there are much larger particles which are brightly doubly refractile (c). 

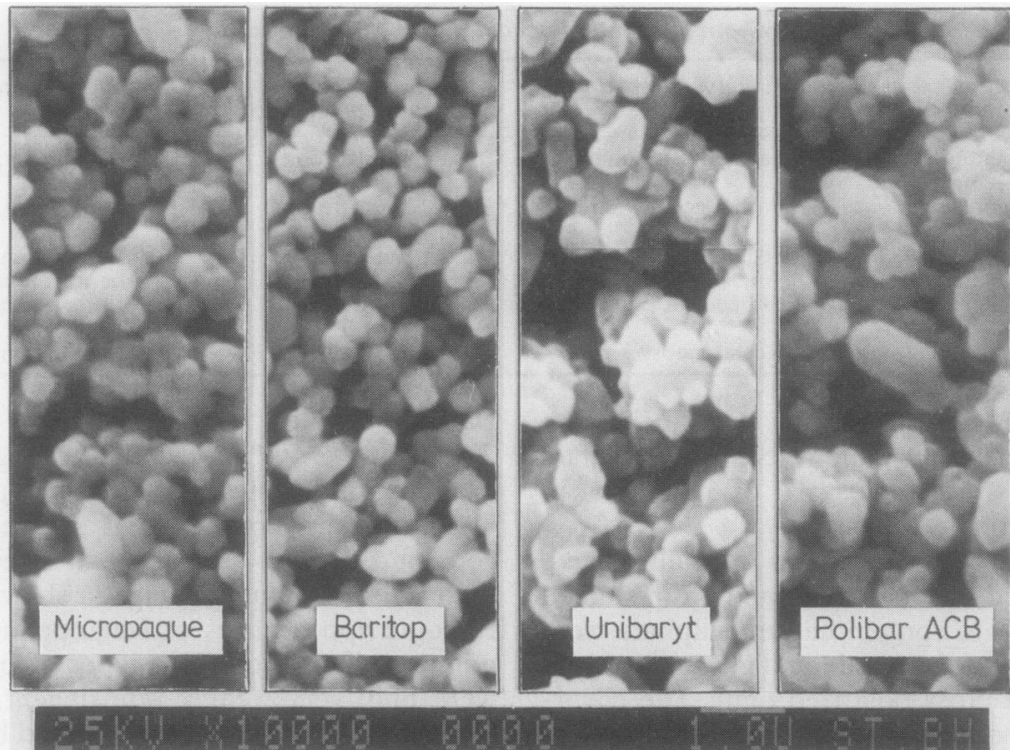

Fig. 3 Secondary electron images of smears of four types of barium sulphate. All are composed of similar sized particles $<1 \mu \mathrm{m}$ in diameter. All $\times 10000$.

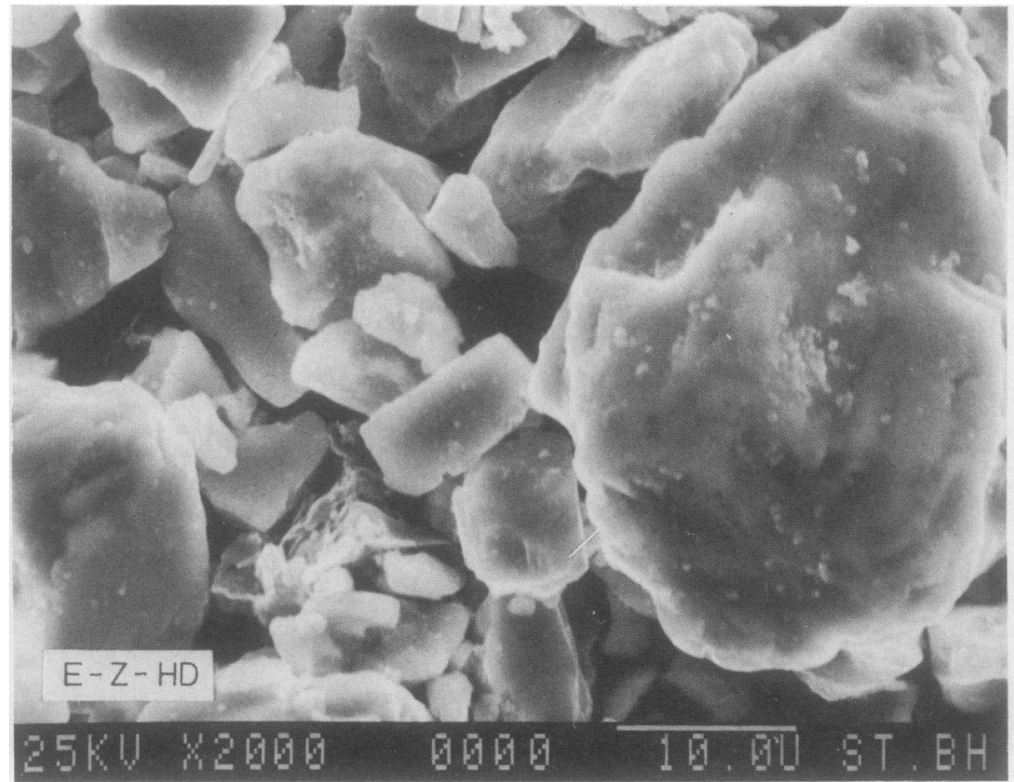

Fig. + Secondary electron image of E-Z-HD. The largest particle in this field is almost $40 \mathrm{um}$ in diameter and the smallest about $1 \mathrm{\mu m} . \times 2000$. 
dard scanning electron microscopy) showed the appearances illustrated in Fig. 3. Even at this magnification $(\times 10000)$ the individual particles still appeared relatively uniform and of similar size in these four preparations. E-Z-HD, viewed at $\times 2000$, included a population of much larger particles of more variable size and shape, in addition to particles of $<1 \mu \mathrm{m}$ diameter (Fig. 4 ).

In the backscattered electron mode, individual particles of all five types of barium sulphate produced considerably brighter images than in the secondary electron mode, but otherwise showed no further striking differences.

On XES, performed under the standard conditions outlined above, the ratio of barium to sulphur varied from sample to sample (Table 2). The average ratio was similar in the four small particle size preparations, but was noticeably higher in E-Z-HD. These findings are discussed briefly below. The only other elements detected were silica and calcium from the supporting glass; in the thickest areas of barium sulphate on the slides there was no background reading for silica and calcium. The heights of the silica and calcium peaks were thus useful indicators of the thickness of the layer of barium sulphate under examination.

\section{PATIENT MATERIAL}

In case 1 the segment of jejunum resected showed extensive mucosal loss - the mucosa being replaced by inflammatory exudate overlying granulation tissue. The submucosa was congested and thickened by fibrous tissue, which extended between the muscle bundles in the lamina propria. The diagnosis of ischaemic enteritis was made on the basis of these appearances. Scattered throughout the full thickness of the submucosa were large bright doubly refractile particles (Fig. 1a, b), some lying free and some apparently in lymphatics. These particles were shown by $x$ ray energy dispersive analysis to be barium sulphate. Their light microscopic (Fig. 1a, b) and scanning electron microscopic appearances (Fig.

Table $2 X$ ray energy spectroscopic analyses of five types of barium sulphate and two histological sections

\begin{tabular}{lll}
\hline Preparation & \multicolumn{2}{l}{ Barium to sulphur ratio } \\
\cline { 2 - 3 } & \multicolumn{1}{l}{ Range } & Average \\
\hline Micropaque & $2 \cdot 44-3 \cdot 70$ & $2 \cdot 86$ \\
Baritop 100 & $2 \cdot 28-3 \cdot 22$ & $2 \cdot 84$ \\
Unibaryt & $2 \cdot 26-3 \cdot 45$ & $2 \cdot 89$ \\
Polibar ACB & $2 \cdot 53-4 \cdot 54$ & 3.03 \\
E-Z-HD & $2 \cdot 65-16 \cdot 69$ & $5 \cdot 22$ \\
Particles in sections from case 1 & $2 \cdot 37-13 \cdot 37$ & $5 \cdot 33$ \\
Particles in sections from case 3 & $2 \cdot 68-4 \cdot 01$ & 3.26 \\
\hline
\end{tabular}

1c, d) showed them to be the larger particles of E-Z-HD. At higher magnification they appeared identical to the particles in Fig. 4.

In case 2 the partial gastrectomy specimen contained two chronic peptic ulcers, each with identical particles of E-Z-HD embedded in the granulation tissue in the base of the ulcer.

In case 3 sections showed the classic appearances of colonic diverticular disease. There was also an area of fibrosis round inflammatory granulation tissue in pericolic fat-interpreted as a healing peridiverticular abscess. In the granulation tissue were numerous macrophages containing finely granular weakly birefringent material suggestive of barium sulphate (Fig. 5a). This material was confirmed by scanning electron microscopy (Fig. 5b, c) and $x$ ray analysis to be one of the small particle forms of barium sulphate.

In case 4 the segment of sigmoid colon removed in the course of refashioning a colostomy showed uncomplicated diverticular disease and contained a $2 \times 1 \mathrm{~cm}$ slightly raised pale mucosal plaque. On section this was found to be composed largely of packed macrophages stuffed with small particles of barium sulphate identical to those seen in case 3 .

Case 5 was a case of ulcerative colitis; the diagnosis had been established by previous biopsies and subtotal colectomy. The biopsy specimen on this occasion showed a granulomatous mucosal lesion including an occasional macrophage containing small particles of barium sulphate as seen in cases 3 and 4 . This case has been described previously."

Detailed XES of the sections, performed under the same standard conditions as for the test samples, gave similar variable readings for barium to sulphur ratios. The results of examining large particle barium sulphate in a section from case 1 and small particle barium sulphate in a section from case 3 are given in Table 2 . The readings in case 1 corresponded to the readings on the test sample of E-Z-HD and the readings in case 3 corresponded closely to the readings from the four small particle sized samples, most closely to Polibar ACB. Cases 1 and 2 were confirmed on inquiry to have been given E-Z-HD. Case 3 was almost certainly given Polibar $\mathrm{ACB}$, though we were not able to establish this absolutely.

\section{Discussion}

Barium sulphate became widely used in gastrointestinal examinations in the early 1900 s. It replaced the "Rieder meal," which was a mixture of bismuth and thick gruel. The soluble salts of barium are highly toxic, but the insoluble sulphate salt appears to be inert and non-toxic. Most barium sulphate is pro- 

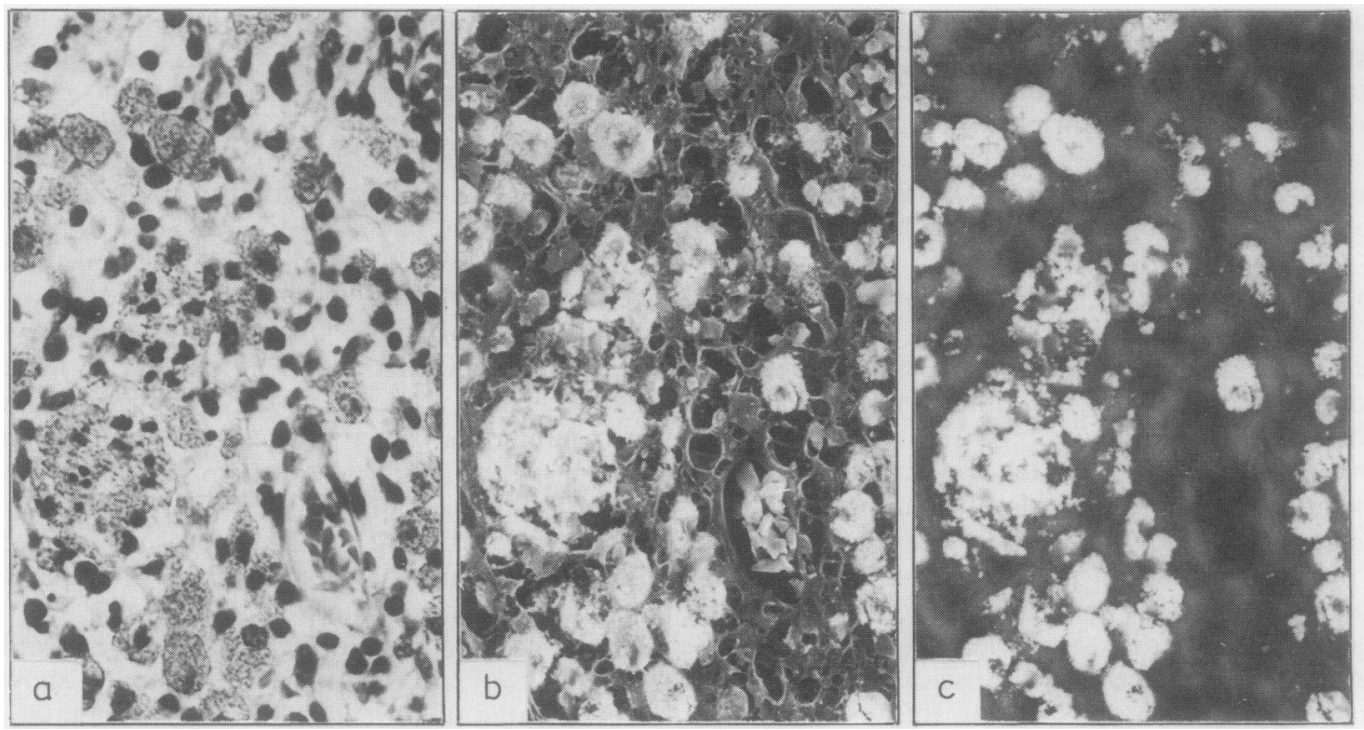

Fig. 5 The same area of the same section (all $\times 390)$ from case 3. (a) is a light micrograph, (b) the secondary, and (c) the backscattered electron image. The finely granular material seen in macrophages proved to be barium sulphate on XES. The patient had had a barium enema.

duced commercially for the paint industry by a chemical process in which sulphuric acid is used to leach out the barium, giving a pure sulphate preparation which is then neutralised and dried. The barium particles produced by this process are of a uniform small size. Barium is extremely adsorbent, and to prevent flocculation of the particles on contact with intestinal secretions the barium is coated with an agent such as methyl cellulose to keep it in suspension.

Most bariums conform to this composition, except high density preparations such as E-Z-HD which have been formulated to give very dense thin layers, so that the surface pattern of the mucosa can be seen in minute radiographic detail. High density bariums are formed from larger particles ground from specially selected samples of barium sulphate. Few suspending agents, if any, are added. They are now in routine use for double contrast examination of the oesophagus, stomach, and duodenum, whereas standard suspensions are used for the examination of the small and large bowel.

We have studied only the barium sulphate preparations used in our two hospitals, but we know from information kindly supplied by $\mathrm{Mr} \mathrm{P}$ Lieberman of Henley's Medical Supplies Ltd that there are other commercially available barium sulphate preparations containing particles larger than $1 \mu \mathrm{m}$. E-Z-Paque is an E-Z-EM company product for single contrast and small bowel studies containing medium sized particles of 3-5 $\mu \mathrm{m}$. We also understand that there is a Micropaque high density product available for upper gastrointestinal work containing similar medium size particles, but we are not aware of other currently used bariums with particle sizes up to the 30-50 $\mu \mathrm{m}$ size seen by us in E-Z-HD.

Although reactions to the presence of barium sulphate in the wall of the gastrointestinal tract are rare, a number have been recorded.$^{1-8}$ Commonest of these is a granulomatous response in the wall of the rectum, but lesions have been recorded in the hepatic capsule after duodenal perforation ${ }^{8}$ and in the lungs after barium embolisation. ${ }^{9}$ The presence of a granulomatous response to barium sulphate can cause diagnostic difficulties. For example, in inflammatory bowel disease the presence of a granuloma usually indicates Crohn's disease rather than ulcerative colitis, but granulomatous reactions to barium sulphate may occur in ulcerative colitis. We have described such a case previously, " and in these cases the amount of barium sulphate present may be small and go undetected by light microscopy.

Sometimes polypoid or ulcerated lesions, which clinically can closely mimic a tumour, develop in relation to barium sulphate in the tissues. This may not happen until long after the barium investigation. Again the commonest site for such lesions is the rectum, where they appear macroscopically raised, whitish or greyish pink, or may be ulcerated with yellow plaque-like areas. 
The histological appearances vary with the age of the lesion, but the one consistent feature is the presence of particles of barium sulphate which most histopathologists recognise as small granular particles, weakly anisotropic in polarised light. The usual appearance of an early barium induced-lesion is of an acute inflammatory reaction, with barium particles surrounded by granulation tissue. Later there is a foreign body type granuloma composed of macrophages and multinucleate giant cells containing phagocytosed barium sulphate particles, and a variable degree of fibroblastic proliferation. Occasionally an abscess may develop at the site of extravasation of barium.

Barium is identifiable histochemically by the rhodizonate method. ${ }^{12}$ The specificity of this method has been questioned, and it is known to produce a reddish brown precipitate with barium, strontium, mercury, and lead.

Larger rhomboidal forms of barium sulphate particle have been reported previously in tissues ${ }^{1}$ but are not, as far as we know, widely recognised by histopathologists as barium sulphate or specifically related by them to E-Z-HD or the upper gastrointestinal tract.

A brief comment on the variation in the barium to sulphur ratio shown in Table 1 is indicated. The higher ratios of barium to sulphur were always found in the thicker areas of the smear or in the large particles of E-Z-HD. At $25 \mathrm{kV}$ an XES detector is more efficient for higher atomic weight elements such as barium (56) and less efficient for lower atomic weight elements such as sulphur (16). It might therefore be expected that the larger the quantity of barium sulphate at which one looks with an XES detector at this voltage, the higher the ratio of barium to sulphur in an individual reading. The lower energy $x$ rays emitted by sulphur are relatively swamped by the higher energy $x$ rays emitted by the large mass of barium. It should be noted that XES as used in our instrument is semi-quantitative. These variations in ratio do not necessarily indicate a variation in composition. Indeed, by lowering the kilovolts to 10 we were able to increase efficiency for the lower atomic weight element sulphur and so reduce the barium to sulphur ratio for a reading on an individual particle.

The use of scanning electron microscopy, backscattered electron imaging, and $x$ ray energy dispersive analysis to identify barium sulphate in tissues is too elaborate for routine purposes. However, only relatively large amounts of barium sulphate are readily identified by light microscopy, and small amounts of pathological importance (for example, causing granulomas in inflammatory bowel disease) may be detected only by $x$ ray analysis. We hope, however, by describing the various appearances of barium sulphate in smears and in tissue sections, that it will be more readily identified by histopathologists using polarised light microscopy.

If precise identification of particles is important then a modification of our method without backscattered electron imaging is possible. A paraffin section can be microincinerated to expose barium sulphate so that it is more easily seen by light microscopy or in a secondary electron image and can be readily analysed. ${ }^{11}$

We thank the North East Thames Regional Health Authority, the St Bartholomew's Hospital Joint Research Board, and the Wellcome Trust, who together funded the purchase of our analytical apparatus, and Miss Helen Trussler for typing the manuscript.

\section{References}

1 Morson BC, Dawson IMP. Gastrointestinal pathology. Oxford: Blackwell Scientific Publications, 1979:578.

${ }^{2}$ Gordon BS, Clyman D. Barium granuloma of the rectum. Gastroenterology 1957;32:943-51.

${ }^{3}$ Lewis JW, Kerstein MD, Koss N. Barium granuloma of the rectum: an uncommon complication of barium enema. Ann Surg 1975; 181:418-23.

${ }^{4}$ Rand AA. Barium granuloma of the rectum. Dis Colon Rectum 1966;9:20-32.

${ }^{s}$ Carney JA, Stephens DH. Intramural barium (barium granuloma) of colon and rectum Gastroenterology 1973;63:316-20.

${ }^{6}$ Cameron HC. Barium proctitis. Proc $R$ Soc Med 1964;57:399400.

${ }^{7}$ Altobelli JA, Yamashita, T, Kratzer GL. Necrotising proctitis caused by injection of barium into the wall of the rectum. Dis Colon Rectum 1970;13:333-5.

${ }^{8}$ Kay S. Tissue reaction to barium sulphate contrast medium. Archives of Pathology 1954;57:279-84.

9 Mahboubi S, Gohel VK, Dalinka MK, Cho SY. Barium embolisation following upper gastrointestinal examination. Radiology 1974;111:301-2.

${ }^{10}$ Crocker PR, Toulson E, Levison DA. Particles in paraffin sections demonstrated in the backscattered electron image (BEI). Micron 1982;13:437-46.

" Crocker PR, Doyle DV, Levison DA. A practical method for the identification of crystalline and particulate matter in body tissues. J Pathol 1980;131:165-73.

${ }_{12}$ Pearse AGE. Histochemistry, theoretical and applied, vol 2. 3rd ed. Edinburgh: Churchill Livingstone, 1972:1142.

Requests for reprints to: Dr DA Levison, Department of Histopathology, St Bartholomew's Hospital, West Smithfield, London EC1A 7BE, England. 